\title{
Effects of motorboat noise on foraging behaviour in Eurasian perch and roach: a field experiment
}

\author{
Carin Magnhagen $^{1, *}$, Kajsa Johansson $^{1}{ }^{1}$ Peter Sigray ${ }^{2}$ \\ ${ }^{1}$ Department of Wildlife, Fish, and Environmental Studies, Swedish University of Agricultural Sciences, 90183 Umeå, Sweden \\ ${ }^{2}$ Department of Underwater Research, Swedish Defence Research Institute, 16490 Stockholm, Sweden
}

\begin{abstract}
The negative impact of anthropogenic noise on marine animals is receiving increasing attention. In order to study the effect of motorboat noise on foraging behaviour in fish, we chose 2 species with different hearing abilities. The roach Rutilus rutilus has a better developed sense of hearing than the Eurasian perch Perca fluviatilis. The study took place in an inlet of the Bothnian Sea where boat traffic is almost absent. Groups of 6 fish were placed in field enclosures containing either one of the species or equal numbers of perch and roach. Half of each enclosure was covered with artificial vegetation. The fish were fed with pieces of saithe twice a day, both with and without the disturbance of an outboard motor. Sound pressure level and particle acceleration were measured for the motor, which was run at $2000 \mathrm{rpm}$. The trials were repeated for $5 \mathrm{~d}$. Perch made fewer feeding attempts during noise exposure compared to controls in the singlespecies enclosures. As the experiment progressed, they gradually increased feeding and time spent in the open area, both with and without noise, indicating habituation. Habitat utilization was affected by the interaction of noise exposure and day. Roach responded to noise exposure with fewer feeding attempts, higher latency to enter the open area, and longer time spent in the vegetation compared to the controls without noise. Roach behaviour changed with time only when housed together with perch. This study, using authentic sound in a natural habitat, shows that noise exposure may affect the feeding behaviour of fish, that the response is species-specific, and that habituation and the presence of other species may modify the effects.
\end{abstract}

KEY WORDS: Anthropogenic noise - Feeding activity - Field enclosures - Perca fluviatilis · Rutilus rutilus . Sound disturbance

\section{INTRODUCTION}

For several decades, human activities have resulted in increasing noise levels in the oceans (Ross 1976, 2005). The increase in low-frequency noise in the Northeast Pacific since the 1960s can be explained by the increase in commercial shipping during the same time period (McDonald et al. 2006). Furthermore, pile driving, different types of sonars, transport ferries, fishing vessels, and recreational boats all contribute to increasing noise levels in the aquatic environment.

There is currently an increase in studies evaluating the impacts of anthropogenic noise disturbance on

${ }^{*}$ Corresponding author: carin.magnhagen@slu.se fish. Noise exposure has been shown to cause temporary hearing threshold shifts (Scholik \& Yan 2002, Smith et al. 2004, Popper et al. 2005) and damage to the auditory systems of fish (McCauley et al. 2003, Casper et al. 2013). Short-term studies have also revealed other negative impacts, such as increased heart rates (Simpson et al. 2005, Graham \& Cooke 2008), and elevated cortisol (stress hormone) levels (Santulli et al. 1999, Smith et al. 2004, Wysocki et al. 2006, Nichols et al. 2015, Johansson et al. 2016). Consequently, noise appears to be a potential stressor for a number of fish species.

Many studies have focused on the masking effects of biologically relevant sound in terms of communi-

() The authors 2017. Open Access under Creative Commons by Attribution Licence. Use, distribution and reproduction are unrestricted. Authors and original publication must be credited. 
cation or detection of predators, food, and obstacles (Wysocki \& Ladich 2005, Gutscher et al. 2011). Boat noise, for example, appears to mask intra-specific communication in a number of vocalizing fish species (Vasconcelos et al. 2007, Codarin et al. 2009, Radford et al. 2014). In addition, noise can have behavioural effects on fish. Fish shoals have been shown to change their vertical movement and their shoaling structure in the presence of passing boats (Drastik \& Kubecka 2005, Sarà et al. 2007) and when exposed to artificial sound (Neo et al. 2014, 2016). Also, increased swimming speed and change of habitat utilization have been found in connection with boating activities (Jacobsen et al. 2014). There may be similarities between anti-predator behaviour and actions caused by human disturbance, both leading to tradeoffs between energy intake and risk avoidance (Frid \& Dill 2002). Escape reactions (Karlsen et al. 2004), cover seeking (McLaughlin \& Kunc 2015), and habitat avoidance (Jacobsen et al. 2014) in response to noise may decrease time spent foraging and thus have negative impacts on fish fitness.

Presently, little is known about the effects of noise on the feeding performance of fish, although there are some studies. Reduction in feeding rates in connection with increased boating activity has been found in mulloway Argyrosomus japonicus (Payne et al. 2015) and in damselfish Chromis chromis (Bracciali et al. 2012). Both three-spined stickleback Gasterosteus aculeatus (Purser \& Radford 2011) and zebrafish Danio rerio (Shafiei Sabet et al. 2015) showed increased food-handling errors when exposed to sound. These studies indicate that noise exposure can alter fish behaviour and affect feeding performance, although the reason for this response is not fully understood. Distraction could be one explanation (Purser \& Radford 2011), and masking effects another, since many fish species use their hearing ability to localize food (Hoin-Radkovsky et al. 1984) or avoid predation (Sand et al. 2000, Wilson et al. 2011). The effects of noise on foraging efforts and food-handling errors in fish have primarily been studied in laboratory experiments using artificial or playback sounds (Purser \& Radford 2011, Voellmy et al. 2014a, McLaughlin \& Kunc 2015, Shafiei Sabet et al. 2015).

In this study, we performed an enclosure study in the Bothnian Bay of Sweden to evaluate the potential impact of authentic sound from a motorboat on the feeding performance and habitat use of fish. We used Eurasian perch Perca fluviatilis and roach Rutilus rutilus, 2 species with different hearing sensitivities, to investigate differences in response to noise expo- sure. We repeated the treatment over several days to explore potential habituation to the sound. We kept the 2 species both separately and together, to determine whether their response to sound could be influenced by the presence of another species.

Eurasian perch (hereafter perch) and roach are among the most common fish species in Sweden and inhabit both freshwater habitats and the brackish water of the Baltic Sea. They are often found together in mixed-species shoals, sometimes in areas where they are likely to encounter various kinds of anthropogenic noise produced by small fishing vessels, transport ferries, and recreational boats. Perch, like most fishes, rely mainly on particle acceleration for their hearing. Still, this entity is rarely measured, despite its high relevance to disturbance (Nedelec et al. 2016). Furthermore, audiograms are usually presented as sound pressure, with the particle motion component usually ignored (but see Horodysky et al. 2008, Radford et al. 2012). In this study, noise production was measured as both sound pressure levels and particle acceleration.

Roach have better hearing ability than perch (Amoser et al. 2004). This is because of the connection between the swim bladder and the ear by the Weberian ossicles, found in cyprinid fish, which gives a higher sensitivity to sound pressure (Hawkins 1993, Popper \& Fay 2011). Roach are sensitive to low frequencies, with the lowest sound pressure level threshold (about $60 \mathrm{~dB}$ re $1 \mu \mathrm{Pa}$ ) between 500 and $1000 \mathrm{~Hz}$, but also have good hearing abilities up to several kHz (Amoser et al. 2004). Perch lack any connection between ear and swim-bladder, and with their lower hearing sensitivity, rely more on acoustic particle motion (Popper \& Fay 2011, Ladich \& Fay 2013). An audiogram shows that perch have sound pressure threshold levels between 90 and $120 \mathrm{~dB}$ re $1 \mu \mathrm{Pa}$ at a frequency range between 100 and $1000 \mathrm{~Hz}$, with best sensitivity at 200 to $300 \mathrm{~Hz}$ (Amoser et al. 2004). The upper limit was found to be $300 \mathrm{~Hz}$ (Wolff 1967, Sand 1974). For both roach and perch, thresholds of particle acceleration have been measured only as a reaction to infrasound, and found to be $27 \mathrm{~dB}$ re $1 \mu \mathrm{m} \mathrm{s}^{-2}$ (roach) and $46 \mathrm{~dB}$ re $1 \mu \mathrm{m} \mathrm{s}^{-2}$ (perch), for frequencies lower than $10 \mathrm{~Hz}$ (H. E. Karlsen pers. comm.).

One hypothesis for our study was that roach would show a stronger response to the boat motor sound than perch, due to higher hearing sensitivity in this species. Based on an earlier study on stress response to noise (Johansson et al. 2016), we also predicted that the response would weaken with time due to habituation. Finally, if the 2 species retrieve informa- 
tion about the environment in different ways (Goodale et al. 2010), interspecific information transfer may lead to different responses to noise exposure in the mixed-species treatment compared to when species are kept separated.

\section{MATERIALS AND METHODS}

\section{Experimental animals and location}

Perch and roach were caught with a beach seine net in Lake Ängersjön located near Umeå, Sweden, and transported to Umeå Marine Science Centre. Fish were held in $1 \mathrm{~m}^{3}$ tanks supplied with running water at natural temperatures and a salinity of ca. 3 ppt. The fish were fed small pieces (ca. $0.5 \mathrm{~cm}^{3}$ ) of saithe Pollachius virens fillet for 2 to $3 \mathrm{wk}$ to acclimate them to brackish water and the new food source. All fish quickly learned to use the food source and readily ate the fish pieces before the start of the experiments. The study was performed in a coastal location outside Hörnefors, Sweden (63 $37^{\prime} \mathrm{N}$, $\left.19^{\circ} 54^{\prime} \mathrm{E}\right)$, in an inlet of the Bothnian Sea where boat traffic is almost absent. Experimental enclosures, made of white PVC mesh (mesh size $0.5 \mathrm{~cm}$ ), with a water volume of $1.125 \mathrm{~m}^{3}$ (area $75 \times 150 \mathrm{~cm}^{2}$, depth $1 \mathrm{~m})$, were placed on the side of a floating pontoon (Fig. 1). The water depth beneath the enclosures was 3.5 to $4.0 \mathrm{~m}$. Artificial vegetation (plastic ribbons, ca. 40 strands, i.e. $70 \mathrm{~m}^{-2}$ ) covered half the area of each enclosure. Between observations, the enclosures were covered with plastic net to avoid attacks from sea birds. A recreational boat (aluminium hull), $5 \mathrm{~m}$ long, with a $70 \mathrm{hp}, 4$-stroke outboard motor was used as the noise source (at $2000 \mathrm{rpm}$ ). It was placed with the bow facing the floating pontoon (Fig. 1). At the stern of the boat, 2 ropes were attached and anchored on land to allow stationary operation of the boat with the outboard motor at $8.0 \mathrm{~m}$ distance from the floating pontoon. We measured the body mass of individual fish and estimated approximate length using length-weight correlations from other fish of the same populations. The mean $( \pm S D)$ size of the fish used in the single-species enclosures was $29.9 \pm$ $11.7 \mathrm{~g}$ for perch (ca. $14.0 \mathrm{~cm}, \mathrm{n}=36$ ) and $29.4 \pm$ $14.6 \mathrm{~g}$ for roach (ca. $14.2 \mathrm{~cm}, \mathrm{n}=36$ ); in the mixedspecies enclosures, mean size was $19.1 \pm 3.9 \mathrm{~g}$ for perch (ca. $12.5 \mathrm{~cm}, \mathrm{n}=18$ ) and $9.7 \pm 2.3 \mathrm{~g}$ for roach (ca. $11.3 \mathrm{~cm}, \mathrm{n}=18$ ). Water temperature was measured once a day; temperature averaged around $18.0^{\circ} \mathrm{C}$ on all occasions.

\section{Experimental procedure}

Experiments were performed with 1 species per enclosure or with mixed species (3 individuals of each) in July and August 2012 and July 2013. Before the experiment, 36 individuals of either perch or roach, or 18 of each species, were randomly selected from the holding stock and transported to the enclosures at the study site. Six individuals were placed in each of the 6 enclosures and left to acclimate for $2 \mathrm{~d}$. The experiment started in the morning (09:00 to 11:00 h) without motorboat noise exposure (control). Each feeding session lasted $5 \mathrm{~min}$, and fish were hand-fed 24 pieces of saithe during this period. The covering net was removed from the open part of the enclosure leaving the vegetated part still covered, and, as a result, all the fish sought shelter in the vegetation. The first saithe piece was dropped in the

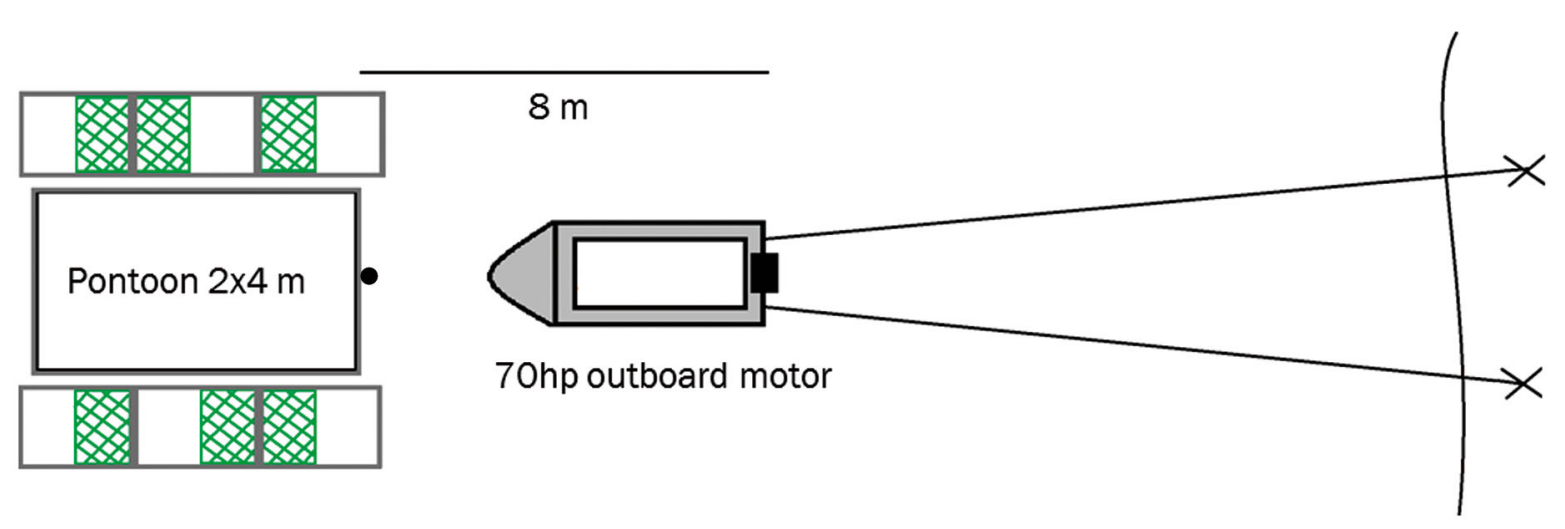

Fig. 1. Experimental setup used in this study. Six enclosures with artificial vegetation (checkered regions) covering half of the area, were mounted on a floating pontoon. A $5 \mathrm{~m}$ long recreational boat with a $70 \mathrm{hp}$, 4-stroke outboard motor was used to create the anthropogenic noise. It was anchored on land and operated from a stationary position, with the motor $8.0 \mathrm{~m}$ from the floating pontoon. Black bullet: location of the hydrophone 
centre of the open area after $20 \mathrm{~s}$, and food delivery continued at $10 \mathrm{~s}$ intervals. The fish pieces slowly sank through the water, and fish were observed attacking the food on its way down. Fish behaviour was video-recorded from above throughout the feeding experiment and was analysed afterwards (see below) using both the film and the spoken comments of observers in the video. In the afternoon (14:00 to 16:00 h), a new feeding session began, this time with noise exposure (for a total time of $30 \mathrm{~min}$ ). The procedure was repeated for 4 more days, with the order of the 'noise' and 'silent' sessions alternated. To avoid a confounding effect between day and feeding order, the order of the enclosures was kept the same, since the data were compared within each enclosure (on the effect of noise and day of experiment).

\section{Sound measurements}

Prior to fish introduction into the enclosures, the sound was characterised in the same location as where the fish study was later conducted. The sound pressure and particle acceleration of the motorboat noise and of background (ambient) noise only (as during controls) were measured (see the Supplement at www.int-res.com/articles/suppl/m564p115 supp.pdf for more details). Particle motion can be expressed as displacement $(\mathrm{m})$, velocity $\left(\mathrm{m} \mathrm{s}^{-1}\right)$ or acceleration $\left(\mathrm{m} \mathrm{s}^{-2}\right)$. The reason for using acceleration in this study and not velocity or displacement is that the hearing organ utilizes acceleration for detecting sound (Fay \& Popper 2000, Martin et al. 2016). It could be argued a fish ear is a biomechanical organ that is similar to an accelerometer, which would favour the use of acceleration. Particle acceleration was measured with a particle motion sensor sensitive to frequencies in the range of 0.1 to $300 \mathrm{~Hz}$, and pressure was measured with a hydrophone (Model LC32; Atlantic Research) sensitive to frequencies in the range of 1 to $170 \mathrm{kHz}$. The 2 sensors were deployed on the short side of the pontoon facing the boat (Fig. 1). Ambient noise level was recorded during a 5 min period. Noise levels from the outboard motor were recorded for $10 \mathrm{~min}$ at each of 7 different distances from the noise source (8 to $19 \mathrm{~m}$ ), in order to establish the relationship between sound levels and distance to the noise source. Equipment used in the particle acceleration measurements was developed by the Department of Meteorology at Stockholm University and the Swedish Defence Research Agency. For detailed descriptions of the acoustic device, see Sigray \& Andersson (2011) and Mueller-Blenkle et al.
(2010). All sound measurements were conducted during 1 d (17 June 2013).

\section{Feeding attempts}

Foraging behaviour was recorded as number of feeding attempts, i.e., when the delivered food item was attacked by a fish. Data were collected from the video recording of the feeding sessions, which lasted 5 min for each enclosure, combined with direct observations during the trials. Feeding attempts were registered as 0 (no attempt) or 1 (attempt) for each food item released (maximum possible number of feeding attempts $=24$ ). In mixed-species enclosures, 2 feeding attempts could be recorded for each food item; one for each fish species. Individual fish of the same species could not be distinguished. Thus, the scores for each enclosure consist of the pooled feeding attempts, estimated separately for each of the 2 species.

\section{Habitat utilization}

Video recordings played at half speed were used for analyses of habitat utilization. The recordings lasted for $5 \mathrm{~min}$ and 2 parameters were measured: (1) latency to enter the open area without vegetation (measured as seconds until the first fish enters the open area) and (2) time spent in the open (number of seconds that at least 1 fish occupied the open area).

\section{Statistical analyses}

Differences in feeding attempts, latency to enter the open area, and time spent in the open area during control and noise exposure were analysed using generalized estimating equation (GEE). The GEE approach is especially suited for longitudinal or repeated-measures data, with a non-normally distributed response variable (Liang \& Zeger 1986). Separate GEEs (Poisson distribution, log-linear link function) were conducted for single-species and mixed-species enclosures, with perch and roach analysed separately. The enclosure ID was added as a subject effect, and the repeats per test ( 5 control sessions +5 noise sessions $=10$ repeats) as a withinsubject effect. The effects of exposure (factor) and day (covariate) were evaluated for 3 dependent variables (feeding attempts, latency to enter open area, and time in the open area) in separate GEEs. All sta- 
tistical analyses were performed in SPSS Statistics 21 (IBM). Particle acceleration and sound pressure data were analysed in Matlab r2008b signal processing software (MathWorks).

\section{RESULTS}

\section{Sound measurements}

Analysis of the measured acoustic data showed that energy levels were low in the frequency range of 50 to $100 \mathrm{~Hz}$ and increased for frequencies higher than $100 \mathrm{~Hz}$ (Fig. 2a). Maximum spectral energy was found in the interval 150 to $600 \mathrm{~Hz}$ (Fig. 2b); at frequencies higher than $600 \mathrm{~Hz}$, spectral energy levels decreased (Fig. 2b). The maximum spectral level calculated in $1 \mathrm{~Hz}$ bands was $126 \mathrm{~dB}$ re $1 \mu \mathrm{Pa}$ (rms). The broadband sound pressure level for frequencies higher than $100 \mathrm{~Hz}$ was $152 \mathrm{~dB}$ re $1 \mu \mathrm{Pa}(\mathrm{rms})$ at $8.2 \mathrm{~m}$. Notable is that the low-frequency part of the spectra, spanning from 0 to $300 \mathrm{~Hz}$, was similar for particle acceleration and sound pressure (Fig. 2a,c). Ambient noise was dominated by sound generated by the pontoon and the sea. Background levels were comparable for frequencies lower than $100 \mathrm{~Hz}$ and considerably lower than the levels obtained with the motor turned on (Fig. 2a-c) for frequencies higher than $100 \mathrm{~Hz}$. Weather conditions were stable throughout the whole study, thus the measured ambient levels can be regarded as representative of the ambient noise experienced by the fish. The difference in distance to the motor between the closest and farthest cage was $3 \mathrm{~m}$. Using the obtained relationship, the differences in sound levels were estimated to be $3 \mathrm{~dB}$ re $1 \mu \mathrm{m} \mathrm{s} \mathrm{s}^{-2}$ and $2 \mathrm{~dB}$ re $1 \mu \mathrm{Pa}$ (Fig. 2d). The same relationship was used to estimate the gradient inside the enclosures. The difference was $1.1 \mathrm{~dB}$ re $1 \mu \mathrm{m} \mathrm{s}^{-2}$ and $0.8 \mathrm{~dB}$ re $1 \mu \mathrm{Pa}$. Thus, during noise exposure, the sound pres- sure and particle acceleration levels at the centre of the closest cage was 152 and at the farthest $150 \mathrm{~dB}$ re $1 \mu \mathrm{Pa}$ (rms), and 75 and $72 \mathrm{~dB}$ re $1 \mu \mathrm{m} \mathrm{s}{ }^{-2}$ (rms), respectively. For more details see the Supplement at www.int-res.com/articles/suppl/m564p115_supp.pdf.

\section{Feeding behaviour}

\section{Perch}

In the single-species enclosures, feeding performance of perch was negatively affected by motorboat noise, with more feeding attempts made during control periods compared to periods with noise exposure (Table 1, Fig. 3). A significant effect of day was found for this species, with more feeding attempts made at
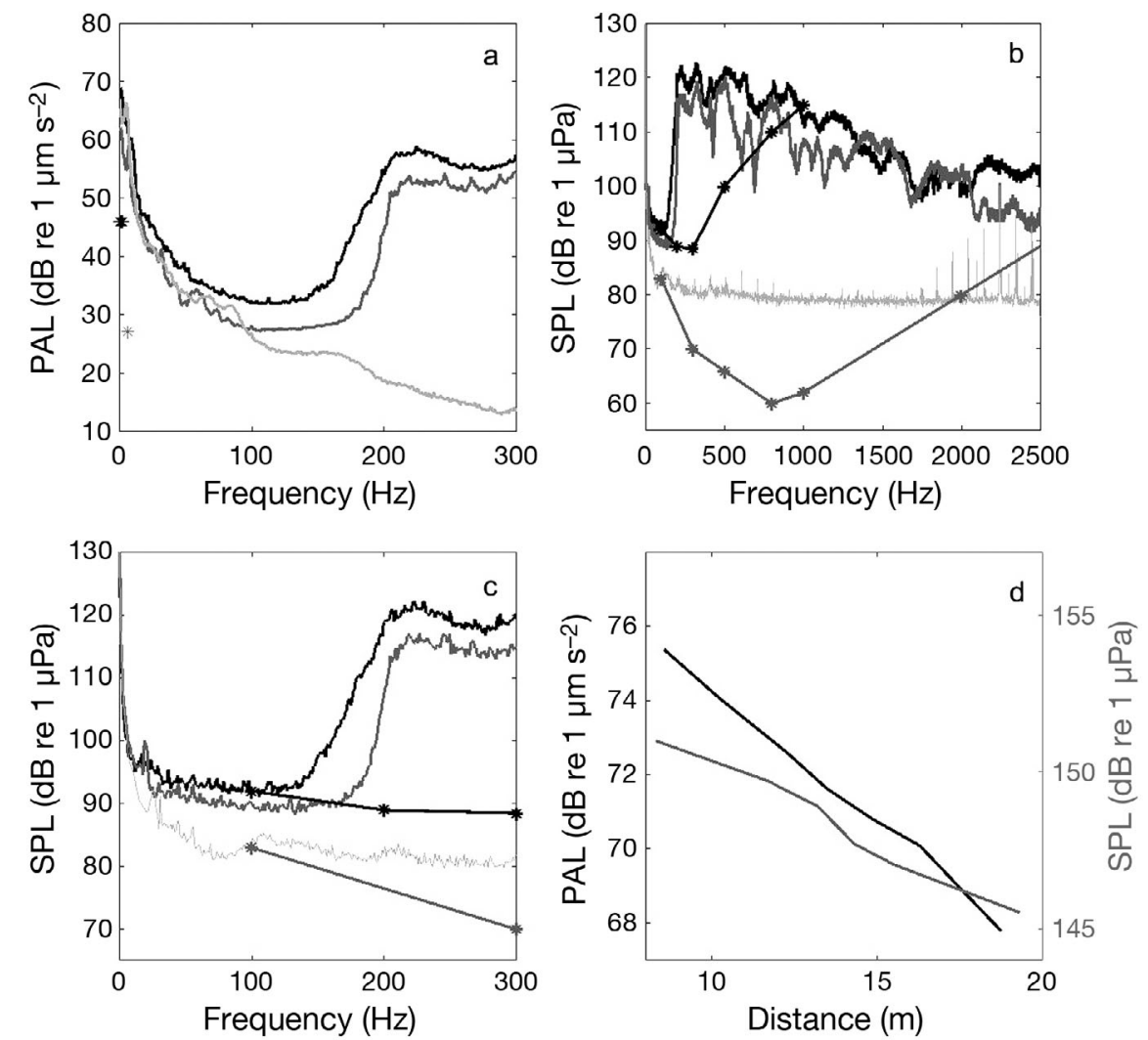

Fig. 2. (a) Particle acceleration level (PAL) measured at a distance of $8.2 \mathrm{~m}$ (black line) and $14.1 \mathrm{~m}$ (grey line) from the outboard motor. The background noise level with the motor off is marked with a light grey line. Black star: hearing threshold for perch Perca fluviatilis; grey star: threshold for roach Rutilus rutilus (H. K. Karlsen pers. comm.). (b) Sound pressure level (SPL) measured at $8.2 \mathrm{~m}$ (black line) and $14.1 \mathrm{~m}$ (grey line) from the motor. Light grey line: background noise levels when the motor was turned off; light grey line with stars: hearing threshold for roach; black line with stars: hearing threshold for perch (from Amoser et al. 2004). (c) The same data as in panel (b) but for the frequency interval 0 to $300 \mathrm{~Hz}$ for comparison with PAL. (d) The attenuation of PAL (black line) and SPL (grey line) with distance from the outboard motor 
Table 1. Generalized estimating equation (GEE) and the effect test (Wald $\chi^{2}$ test) for perch Perca fluviatilis and roach Rutilus rutilus in single-species enclosures. The effects of exposure (factor) and day (covariate) were evaluated for 3 dependent variables: feeding attempts, latency to enter the open area, and time spent in the open area. Significant values are in bold; ${ }^{*} 0.05<\mathrm{p}<0.1$

\begin{tabular}{|lrrrr|}
\hline Single-species & \multicolumn{2}{c}{ Perch } & \multicolumn{2}{c|}{ Roach } \\
Variable & Wald $\chi^{2}$ & $\mathrm{p}$ & Wald $\chi^{2}$ & $\mathrm{p}$ \\
\hline Feeding attempt & & & & \\
Exposure & $\mathbf{8 . 7 0 4}$ & $\mathbf{0 . 0 0 3}$ & $\mathbf{1 6 . 6 7 1}$ & $<\mathbf{0 . 0 0 1}$ \\
Day & $\mathbf{5 2 . 0 8 6}$ & $\mathbf{< . 0 0 1}$ & 0.434 & 0.510 \\
Exposure $\times$ day & 1.241 & 0.265 & 0.749 & 0.387 \\
Latency to enter the open area & & & \\
Exposure & 0.086 & 0.770 & 3.624 & $0.057^{*}$ \\
Day & $\mathbf{9 . 1 0 1}$ & $\mathbf{0 . 0 0 3}$ & 0.001 & 0.972 \\
Exposure $\times$ day & 0.560 & 0.454 & 0.648 & 0.421 \\
Time in the open area & & & & \\
Exposure & 0.559 & 0.455 & 3.482 & $0.062^{*}$ \\
Day & $\mathbf{1 4 . 5 5 6}$ & $<\mathbf{0 . 0 0 1}$ & 1.059 & 0.303 \\
Exposure $\times$ day & 0.105 & 0.746 & 0.375 & 0.540 \\
\hline
\end{tabular}

the end of the experiment compared to the start, both during noise exposure and control treatments. No feeding attempts were seen during the first day of the experiments. In the mixed-species enclosures, no effect of noise disturbance was observed in perch, but also here a day effect was found, with very few or no feeding attempts during the first $2 \mathrm{~d}$ (Table 2, Fig. 3).

Roach

In single-species enclosures with roach, there were significantly fewer feeding attempts made during noise exposure treatments compared with the controls, and no effect of day was found (Table 1, Fig. 3). In the mixed-species enclosures, number of feeding attempts increased significantly with day, resulting in a significant interaction between noise treatment and day (Table 2, Fig. 3). During noise exposure, no feeding attempts were observed for the first $2 \mathrm{~d}$, although a few were made during the control treatment during that time (Fig. 3).

\section{Habitat utilization}

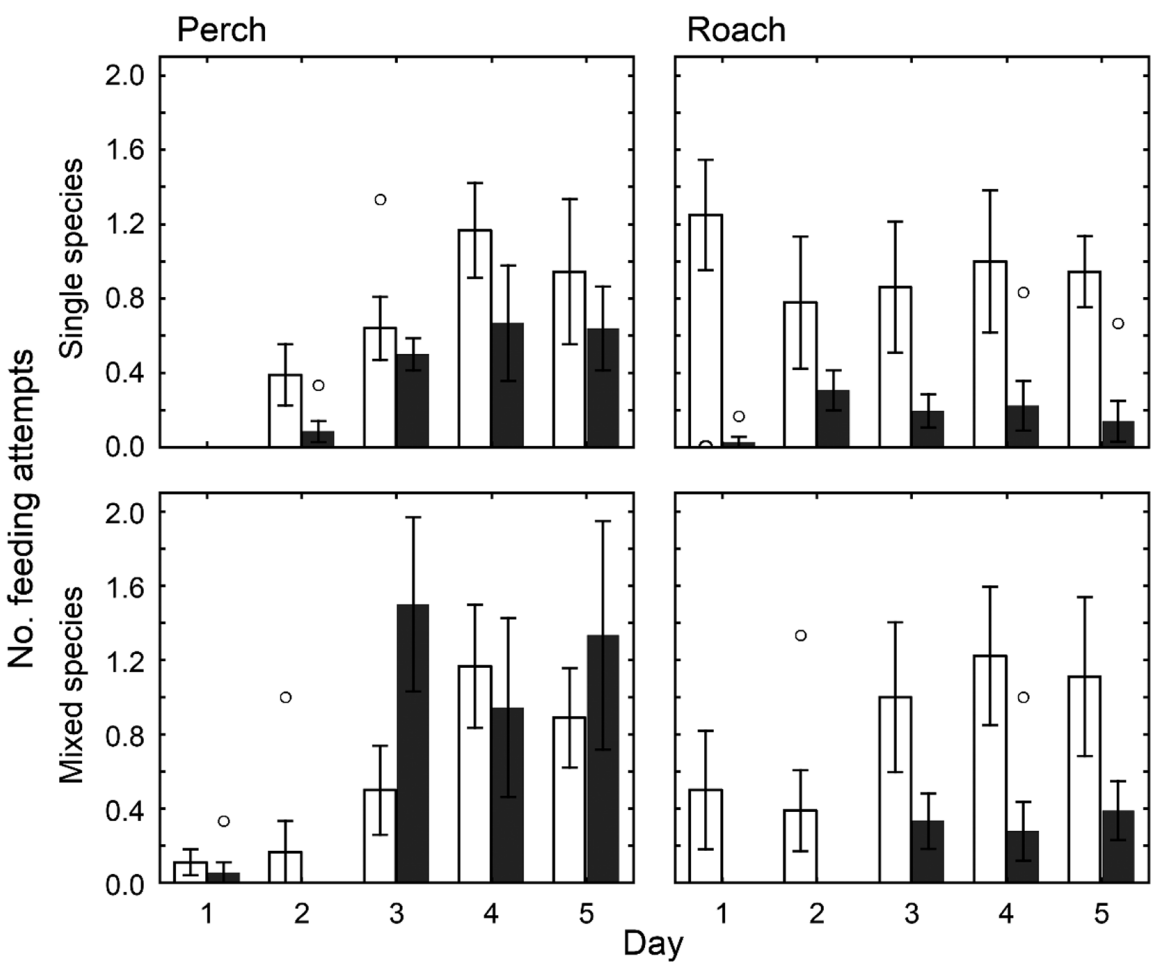

Fig. 3. Mean $( \pm \mathrm{SE})$ number of feeding attempts of perch Perca fluviatilis and roach Rutilus rutilus in single- and mixed-species enclosures when subjected to either silent (control) conditions (open bars) or noise exposure (filled bars). Scores show the average number of feeding attempts for 6 individuals in the single-species enclosure and 3 individuals in the mixed-species enclosure. Circles denote outliers

\section{Perch}

In the single-species enclosures, only day had a significant effect of the latency of perch to enter the open area and the time spent in the open, but there was no effect of noise exposure (Table 1, Fig. 4). No fish entered the open area the first day of the experiment, but latency to leave the vegetation for the open area decreased with time; that is, it took less time for the first fish to enter the open area at the end of the experiment compared to the start (Fig. 4). Noise did not have any effect on the latency of perch to enter open areas in mixed-species enclosures, but time spent in the open differed between noise exposure and control (Table 2, Fig. 4). There was, however, a significant interaction between noise exposure and day, and the effect of the noise showed different directions during different days (Fig. 4). 
Table 2. Generalized estimating equation (GEE) and the effect test (Wald $\chi^{2}$ test) for perch Perca fluviatilis and roach Rutilus rutilus in mixed-species enclosures. The effects of exposure (factor) and day (covariate) were evaluated for 3 dependent variables: feeding attempts, latency to enter the open area, and time spent in the open area. Significant values are in bold

\begin{tabular}{|lrrrr|}
\hline Mixed-species & \multicolumn{2}{c}{ Perch } & \multicolumn{2}{c|}{ Roach } \\
Variable & Wald $\chi^{2}$ & $\mathrm{p}$ & Wald $\chi^{2}$ & $\mathrm{p}$ \\
\hline & & & & \\
Feeding attempt & & & & \\
Exposure & 1.021 & 0.312 & $\mathbf{1 9 . 5 2 9}$ & $<\mathbf{0 . 0 0 1}$ \\
Day & $\mathbf{2 4 . 0 6 5}$ & $<\mathbf{0 . 0 0 1}$ & $\mathbf{1 7 . 9 4 3}$ & $<\mathbf{0 . 0 0 1}$ \\
Exposure $\times$ day & 0.019 & 0.922 & $\mathbf{1 2 . 3 2 4}$ & $<\mathbf{0 . 0 0 1}$ \\
Latency to enter the open area & & & \\
Exposure & 0.629 & 0.428 & $\mathbf{5 . 2 0 2}$ & $\mathbf{0 . 0 2 3}$ \\
Day & $\mathbf{5 . 3 7 1}$ & $\mathbf{0 . 0 2 0}$ & $\mathbf{4 . 1 2 3}$ & $\mathbf{0 . 0 4 2}$ \\
Exposure $\times$ day & 0.219 & 0.640 & 0.164 & 0.685 \\
Time in the open area & & & & \\
Exposure & $\mathbf{5 . 1 0 4}$ & $\mathbf{0 . 0 2 4}$ & $\mathbf{3 4 . 6 2 4}$ & $<\mathbf{0 . 0 0 1}$ \\
Day & $\mathbf{2 9 . 1 0 5}$ & $<\mathbf{0 . 0 0 1}$ & $\mathbf{1 2 9 . 9 6 1}$ & $<\mathbf{0 . 0 0 1}$ \\
Exposure $\times$ day & $\mathbf{6 . 8 1 2}$ & $\mathbf{0 . 0 0 9}$ & $\mathbf{9 9 . 1 1 4}$ & $<\mathbf{0 . 0 0 1}$ \\
\hline
\end{tabular}

\section{DISCUSSION}

Our results show that motorboat noise has the potential to affect the foraging behaviour of both perch and roach. Roach, in both single- and mixedspecies enclosures, made fewer feeding attempts during treatments with motorboat noise compared to the silent control condition. In perch, the same pattern was found in the single-, but not in the mixedspecies enclosures. Lower feeding frequencies and changes in diet composition have previously been observed in both the Mediterranean damselfish Chromis chromis and the mulloway Argyrosomus japonicus during periods of increased boating activity (Bracciali et al. 2012, Payne et al. 2015). The altered mulloway behaviour was suggested to be caused by stress, which is a common consequence of noise disturbance (Kight \& Swaddle 2011). Ship noise has also been shown to be a stressor for 3 freshwater fish species (common carp Cyprinus carpio, gudgeon Gobio gobio, and perch), inducing higher cortisol release (Wysocki et al. 2006). Similarly, motorboat noise caused an increase in cortisol levels in both perch and roach (Johansson et al. 2016), indicating
Roach

Roach from the single-species enclosure appeared to have a shorter latency to enter, and spent more time in the open area during control conditions compared to periods with noise disturbance (Fig. 4), but the observed differences were only close to significant (Table 1). A significant difference between sound treatments was, however, observed for both latency and time spent in the open area in the mixed-species enclosure (Table 2, Figs. 4 \& 5). A significant day effect was also found for roach in the mixed-species enclosure for both these measures (Table 2, Figs. 4 \& 5). However, a significant interaction between noise treatment and day and time spent in the open was explained by the data from the last day, during which the fish decreased time spent in the open from the previous day in the control, but increased in the noise treatment (Fig. 5).

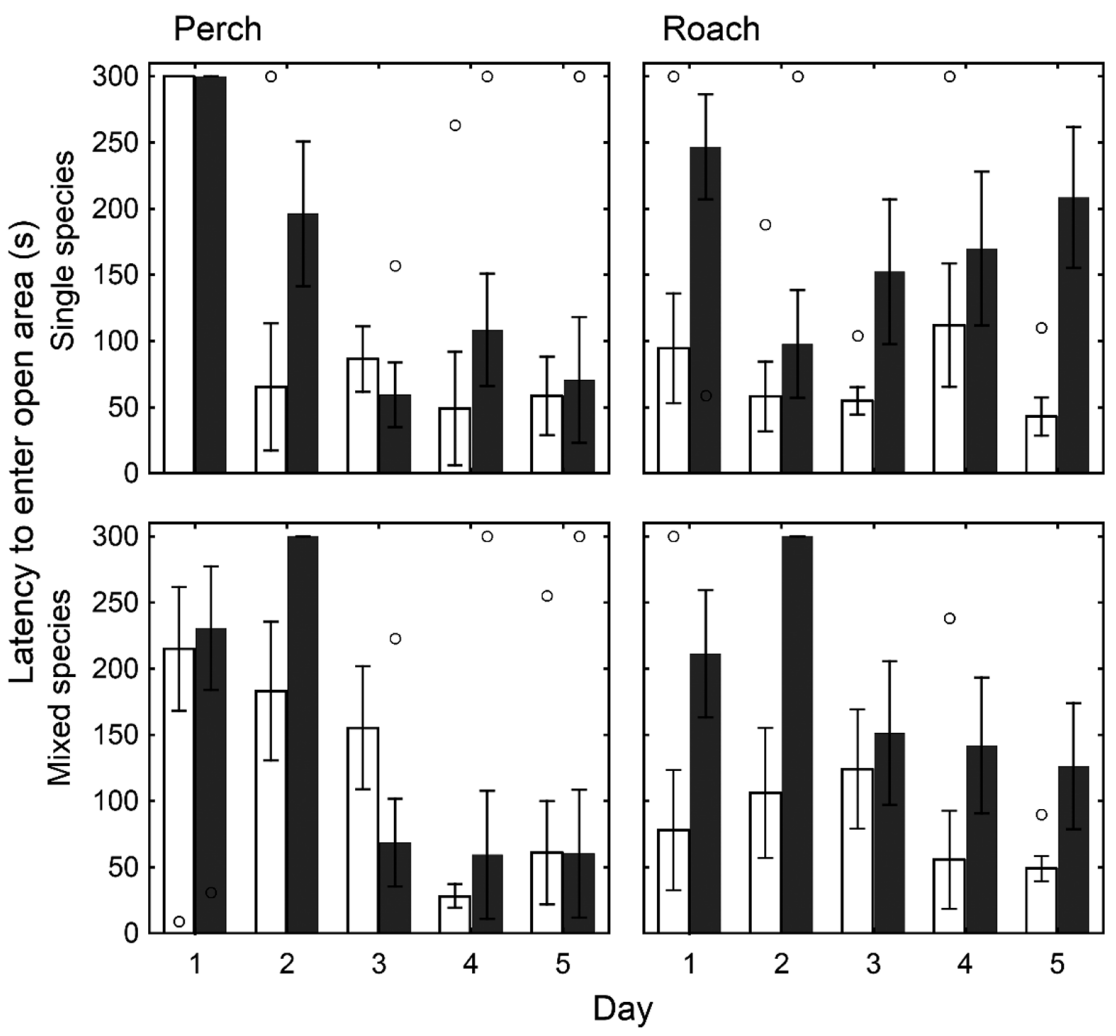

Fig. 4. Mean $( \pm \mathrm{SE})$ time until the first fish entered the open area for perch Perca fluviatilis and roach Rutilus rutilus in single- and mixed-species enclosures, when subjected to either silent (control) conditions (open bars) or noise exposure (filled bars). Circles denote outliers 


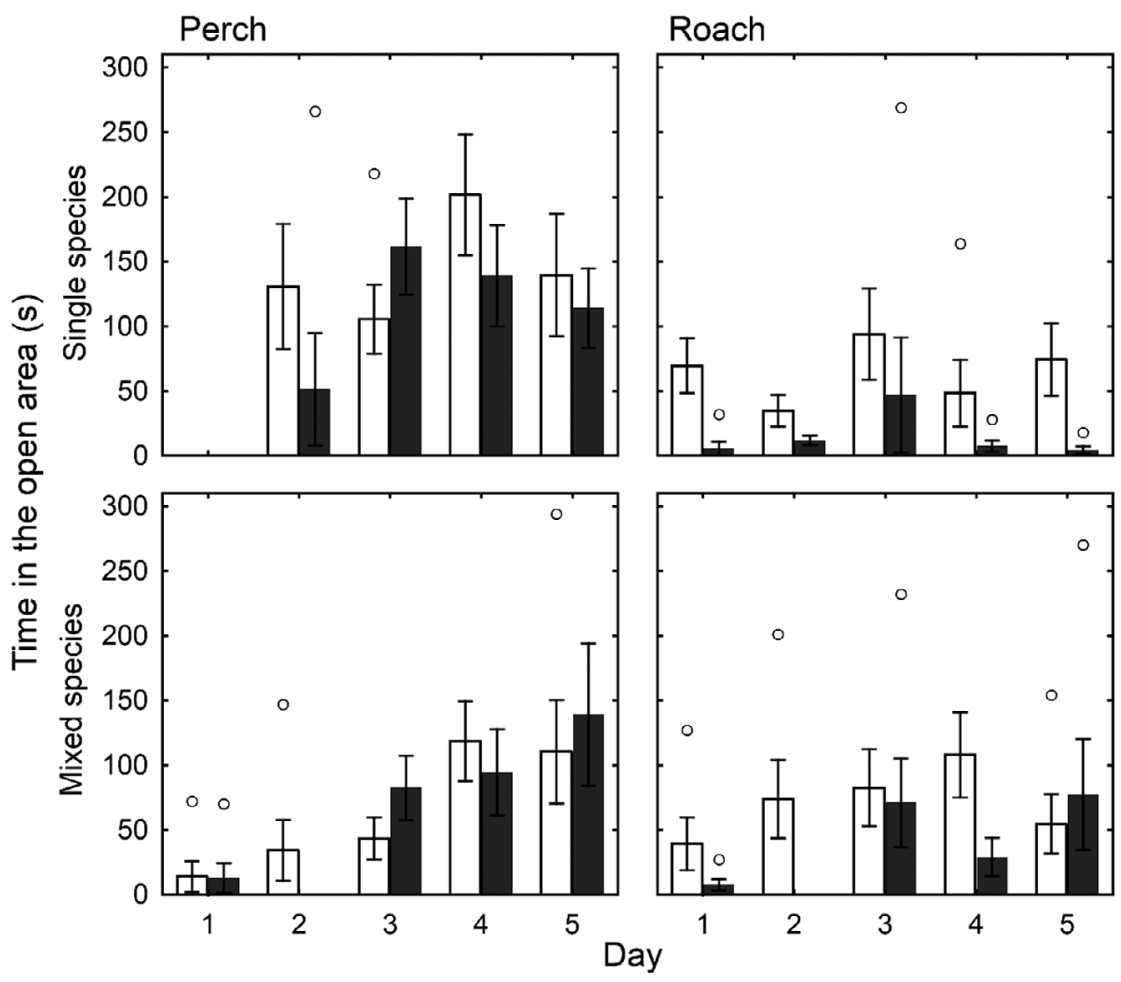

Fig. 5. Mean $( \pm \mathrm{SE})$ time when at least 1 individual was observed in the open area for perch Perca fluviatilis and roach Rutilus rutilus in single- and mixed-species enclosures, when subjected to either silent (control) conditions (open bars) or noise exposure (filled bars). Circles denote outliers

that stress response could be a possible explanation for the results in the current study.

However, there could be several reasons for reduced feeding performance during noise exposure, potentially diverging between perch and roach. Boat noise can cause a narrowing or shift in attention, distracting feeding animals and causing them to miss or ignore prey items. Chan et al. (2010) found support for this hypothesis in a playback experiment with the Caribbean hermit crab Coenobita clypeatus. The reduced foraging performance in three-spined sticklebacks during noise exposure was also explained by attention shift (Purser \& Radford 2011). Furthermore, boat noise may mask sound produced by prey (in this study, sound produced by falling food items) (Amoser et al. 2004). Noise impacts on prey detection in fish have yet to be described - although this is relevant, since some fish species rely on their hearing abilities to find food (Hoin-Radkovsky et al. 1984). The 2 species in our study differ in their hearing sensitivities (Amoser et al. 2004). Perch are considered to rely mainly on particle acceleration for hearing, and are most sensitive to low-frequency sounds. In our study, the boat motor emitted high-frequency sounds, with maximum spectral energy in the interval of 150 to
$600 \mathrm{~Hz}$; measurements of sound pressure and particle acceleration follow each other quite closely. Information on particle acceleration thresholds are not available for perch and roach at these frequencies; however, studies on other fish species have shown that thresholds are lowest at low frequencies $(<200 \mathrm{~Hz})$ (Horodysky et al. 2008, Radford et al. 2012). The high frequencies produced by the motor would, to a high degree, be below the hearing threshold of perch, at least regarding sound pressure. Thus, a masking effect is unlikely to be the reason that perch in the singlespecies enclosures made fewer feeding attempts during noise exposure than during controls. Still, the perch seemed to perceive the noise in some way, possibly by particle acceleration, and their reaction may be a result of distraction or stress. Roach are more sensitive to sound pressure at the frequencies measured in the present study. The effect of noise exposure on their feeding could be explained by stress, distraction, or masking, but we cannot identify the accurate mechanisms behind their response to the disturbance.

The perch did not perform any feeding attempts on the first day in the single-species enclosures, which suggest that they had not fully adapted to the new environment. After that, although the perch consistently made fewer feeding attempts during noise exposure, the number of attempts increased with day during both treatments, indicating habituation. This is supported by the fact that latency to enter the open area also decreased with day in perch. In contrast, roach did not show any trend in the number of feeding attempts made during noise exposure, and no decrease in latency to enter the open area was found over the $5 \mathrm{~d}$ of the study. This implies that the roach were more disturbed by the noise than the perch, and did not habituate. The same pattern was found by Jacobsen et al. (2014), with perch (but not roach) seemingly habituating to boat noise. Habituation to noise exposure was also found in a study on stress response in perch and roach (Johansson et al. 2016). In that study, perch showed elevated cortisol levels after being subjected only once to motorboat sound, but after $11 \mathrm{~d}$ of exposure $\left(2 \times 30 \mathrm{~min} \mathrm{~d}^{-1}\right)$, cortisol 
levels did not differ between noise treatments and controls (Johansson et al. 2016). In roach, cortisol levels were higher in the short-term compared to the long-term study, but with overall higher levels in groups exposed to noise compared to control groups (Johansson et al. 2016). Similarly, red drum Scianenops ocellatus and spotted sea trout Cynoscion nebulosus showed elevated cortisol levels after shortterm but not long-term exposure to playback recordings of boat noise (Spiga et al. 2012). The present study was a short-term study (duration $5 \mathrm{~d}$ ). For that reason, we cannot say if the effects of noise exposure would persist over a longer time period. Both zebrafish (Shafiei Sabet et al. 2015) and European seabass Dicentrarchus labrax (Neo et al. 2014) showed stronger negative effects when sound was emitted intermittently compared to continuously, in terms of activity, foraging performance, and behavioural recovery. Thus, both the duration and the temporal pattern of noise exposure may be important for longterm effects on fish behaviour and fitness.

Anthropogenic noise exposure may have negative effects on predator detection, for example, in terms of increased reaction times as shown in shore crabs Carcinus maenas and juvenile European eels Anguilla anguilla (Wale et al. 2013, Simpson et al. 2015). In contrast, three-spined sticklebacks responded faster to a visual predator stimulus during noise (playback) exposure than during control conditions (Voellmy et al. $2014 \mathrm{~b})$. The heightened cautiousness during sound exposure could be caused by stress (Charmandari et al. 2005), but it could also be a compensatory response to auditory masking (Rabin et al. 2006). Latency to enter a novel area is often analysed as a proxy for reduced risk-taking behaviour and boldness (Brown et al. 2005, Magnhagen 2007). In our study, the latency to enter the open area was longer for roach in mixed-species enclosures during noise disturbance compared to control treatments, with a similar trend in the singlespecies enclosures. In general, roach spent less time in the open during noise exposure than during control conditions, but in the mixed-species enclosures this was mainly found during the first $2 \mathrm{~d}$. Noise exposure can trigger anti-predator behaviour (Frid \& Dill 2002), such as seeking shelter in vegetation. Both perch and roach may seek shelter under predation risk (Persson 1991). Potentially, this could explain the treatment effect on habitat utilization in roach. Noise exposure had no effects in perch regarding latency to enter the open area, and time spent in the open area varied with day with either more time during silence or during noise exposure. Thus, perch did not seem to perceive the noise as a threat.
In our study both, roach and perch responded to the boat motor noise, but the results differed between species. In another study, roach tagged with acoustic transmitters aggregated and moved away from a running outboard motor, while tagged perch only showed a short-term reaction to the motor noise and did not change habitat (Jacobsen et al. 2014). Sympatric minnows Phoxinus phoxinus and threespined sticklebacks both exhibited a reduction in foraging success when exposed to the playback of ship noise, although different mechanisms may explain this effect (Voellmy et al. 2014a). Another study, comparing the response to noise in 2 species with different hearing abilities (zebrafish and Lake Victoria cichlid Haplochromis piceatus), found both similar and species-specific responses and concluded that responses are not necessarily related to differences in hearing (Shafiei Sabet et al. 2016).

Since roach and perch often co-occur in their natural habitat, we kept the 2 species separate and together, to determine whether their behaviour was influenced by inter-specific interactions. For perch, the number of feeding attempts per individual was higher during noise exposure in the mixed-species compared to the single-species enclosures. However, it is likely that the reduced foraging in roach affected the feeding behaviour of perch by decreasing competition for the food that was delivered. In roach, both number of feeding attempts and utilization of the open area changed with time in the mixed-species, but not in the single-species enclosures. In the single-species treatment, the roach were larger than in the mixed-species treatments, but the response to noise exposure was still similar. The significant interaction between noise exposure and time, only found in the mixed-species treatment, could possibly be affected by the smaller size of the fish in this treatment. However, it is more likely that the change in behaviour with time was due to an influence of the perch, which exhibited less of a reaction to the noise exposure, and seemed to become habituated in all treatments. This result is in line with other findings that animals select habitats using heterospecific information (Goodale et al. 2010).

Foraging efforts and food handling errors in fish during noise disturbance have primarily been studied in laboratory experiments (Purser \& Radford 2011, Voellmy et al. 2014a, McLaughlin \& Kunc 2015, Shafiei Sabet et al. 2015). Experiments on the effects of noise disturbance on foraging are rarely conducted outdoors (but see Bracciali et al. 2012, Payne et al. 2015). Thus, our study is among the first to study noise effects in fish under natural environmental conditions. 
Another advantage of our study was that a real motorboat with an outboard motor was used to produce authentic noise. In general, most studies on noise effects on aquatic organisms use artificial sound or playback recordings. It is important to remember that the recordings used in most tank-based experiments can be very different from those produced by actual sound sources (Akamatsu et al. 2002). However, to fully understand natural conditions, future studies will have to include free-swimming (wild) individuals (e.g. Jacobsen et al. 2014). In order to understand the acoustic conditions for different fish species, both particle acceleration and sound pressure should be measured, as was done here, since fish with different hearing abilities use different components of sound for their hearing (Nedelec et al. 2016).

In conclusion, using authentic sound in a natural habitat, this study has shown that noise exposure may affect the feeding behaviour of fish, that the response is species-specific, and that habituation and the presence of other species may modify the effects. The knowledge obtained here is crucial in order to predict species-specific long-term effects of noise. For example, noise can affect species like roach and perch and lower their feeding efficiency-which can have important implications for fitness, animal welfare, and conservation (Voellmy et al. 2016). Our study also suggests that the effect of anthropogenic noise should be considered in the management of fish communities and should be included in future analyses of species interactions, growth, and reproductive success.

Acknowledgements. This study was financed by the Centre for Environmental Research (CMF) in Umeå, Sweden. The experiments in this study were approved by the local ethics committee of the Swedish National Board for Laboratory Animals (CFN, A91-10). We thank the staff at the Umeå Marine Research Centre for indispensable help with the experimental setup. Three anonymous reviewers gave valuable advice on an earlier version of the manuscript.

\section{LITERATURE CITED}

Akamatsu T, Okumura T, Novarini N, Yan HY (2002) Empirical refinements applicable to the recording of fish sounds in small tanks. J Acoust Soc Am 112:3073-3082

Amoser S, Wysocki LE, Ladich F (2004) Noise emission during the first powerboat race in an Alpine lake and potential impact on fish communities. J Acoust Soc Am 116: 3789-3797

Bracciali C, Campobello D, Giacoma C, Sara G (2012) Effects of nautical traffic and noise on foraging patterns of Mediterranean damselfish (Chromis chromis). PLOS ONE 7:e40582

B Brown C, Jones F, Braithwaite V (2005) In situ examination of boldness-shyness traits in the tropical poeciliid, Brachyraphis episcopi. Anim Behav 70:1003-1009
Casper BM, Smith ME, Halvorsen MB, Sun H, Carlson TJ, Popper AN (2013) Effects of exposure to pile driving sounds on fish inner ear tissues. Comp Biochem Physiol A Mol Integr Physiol 166:352-360

* Chan AAYH, Giraldo-Perez P, Smith S, Blumstein DT (2010) Anthropogenic noise affects risk assessment and attention: the distracted prey hypothesis. Biol Lett 6: $458-461$

Charmandari E, Tsigos C, Chrousos G (2005) Endocrinology of the stress response. Annu Rev Physiol 67:259-284

* Codarin A, Wysocki LE, Ladich F, Picciulin M (2009) Effects of ambient and boat noise on hearing and communication in three fish species living in a marine protected area (Miramare, Italy). Mar Pollut Bull 58:1880-1887

* Drastik V, Kubecka J (2005) Fish avoidance of acoustic survey boat in shallow waters. Fish Res 72:219-228

Fay RR, Popper AN (2000) Evolution of hearing in vertebrates: the inner ears and processing. Hear Res 149:1-10

Frid A, Dill L (2002) Human-caused disturbance stimuli as a form of predation risk. Conserv Ecol 6:11

*Goodale E, Beauchamp G, Magrath RD, Nieh JC, Ruxton GD (2010) Interspecific information transfer influences animal community structure. Trends Ecol Evol 25:354-361

*Graham AL, Cooke SJ (2008) The effects of noise disturbance from various recreational boating activities common to inland waters on the cardiac physiology of a freshwater fish, the largemouth bass (Micropterus salmoides). Aquat Conserv 18:1315-1324

*Gutscher M, Wysocki LE, Ladich F (2011) Effects of aquarium and pond noise on hearing sensitivity in an otophysine fish. Bioacoustics 20:117-136

Hawkins AD (1993) Underwater sound and fish behaviour. In: Pitcher TJ (ed) Behaviour of teleost fishes. Chapman \& Hall, London, p 129-169

Hoin-Radkovsky I, Bleckmann H, Schwartz E (1984) Determination of source distance in the surface-feeding fish Pantodon buchholzi Pantodontidae. Anim Behav 32: 840-851

*Horodysky AZ, Brill RW, Fine ML, Musick JA, Latour RJ (2008) Acoustic pressure and particle motion thresholds in six sciaenid fishes. J Exp Biol 211:1504-1511

Jacobsen L, Baktoft H, Jepsen N, Aarestrup K, Berg S, Skov C (2014) Effect of boat noise and angling on lake fish behaviour. J Fish Biol 84:1768-1780

* Johansson K, Sigray P, Backström T, Magnhagen C (2016) Stress response and habituation to motorboat noise in two coastal fish species in the Bothnian sea. Adv Exp Med Biol 875:513-521

* Karlsen HE, Piddington RW, Enger PS, Sand O (2004) Infrasound initiates directional fast-start escape responses in juvenile roach Rutilus rutilus. J Exp Biol 207:4185-4193

Kight CR, Swaddle JP (2011) How and why environmental noise impacts animals: an integrative, mechanistic review. Ecol Lett 14:1052-1061

Ladich F, Fay RR (2013) Auditory evoked potential audiometry in fish. Rev Fish Biol Fish 23:317-364

Liang KY, Zeger SL (1986) Longitudinal data analysis using generalized linear-models. Biometrika 73:13-22

Magnhagen C (2007) Social influence on the correlation between behaviours in young-of-the-year perch. Behav Ecol Sociobiol 61:525-531

Martin B, Zeddies DG, Gaudet B, Richard J (2016) Evaluation of three sensor types for particle motion measurement. Adv Exp Med Biol 875:679-686

McCauley RD, Fewtrell J, Popper AN (2003) High intensity anthropogenic sound damages fish ears. J Acoust Soc Am 113:638-642 
McDonald MA, Hildebrand JA, Wiggins SM (2006) Increases in deep ocean ambient noise in the Northeast Pacific west of San Nicolas Island, California. J Acoust Soc Am 120:711-718

McLaughlin KE, Kunc HP (2015) Changes in the acoustic environment alter the foraging and sheltering behaviour of the cichlid Amititlania nigrofasciata. Behav Processes 116:75-79

Mueller-Blenkle C, McGregor PK, Gill AB, Andersson MH and others (2010) Effects of pile-driving noise on the behaviour of marine fish. COWRIE Tech Rep Ref Fish 0608, Cefas, Lowestoft

* Nedelec SL, Campbell J, Radford AN, Simpson SD, Merchant ND (2016) Particle motion: the missing link in underwater acoustic ecology. Methods Ecol Evol 7:836-842

Neo YY, Seitz J, Kastelein RA, Winter HV, ten Cate C, Slabbekoorn H (2014) Temporal structure of sound affects behavioural recovery from noise impact in European seabass. Biol Conserv 178:65-73

Neo YY, Hubert J, Bolle L, Winter HV, ten Cate C, Slabbekoorn H (2016) Sound exposure changes European seabass behaviour in a large outdoor floating pen: effects of temporal structure and a ramp-up procedure. Environ Pollut 214:26-34

Nichols TA, Anderson TW, Sirovic A (2015) Intermittent noise induces physiological stress in a coastal marine fish. PLOS ONE 10:e0139157

Payne NL, van der Meulen DE, Suthers IM, Gray CA, Taylor MD (2015) Foraging intensity of wild mulloway Argyrosomus japonicus decreases with increasing anthropogenic disturbance. Mar Biol 162:539-546

*Persson L (1991) Behavioral response to predators reverses the outcome of competition between prey species. Behav Ecol Sociobiol 28:101-105

Popper AN, Fay RR (2011) Rethinking sound detection by fishes. Hear Res 273:25-36

Popper AN, Smith ME, Cott PA, Hanna BW, MacGillivray AO, Austin ME, Mann DA (2005) Effects of exposure to seismic airgun use on hearing of three fish species. J Acoust Soc Am 117:3958-3971

Purser J, Radford AN (2011) Acoustic noise induces attention shifts and reduces foraging performance in threespined sticklebacks (Gasterosteus aculeatus). PLOS ONE 6:e17478

Rabin LA, Coss RG, Owings DH (2006) The effects of wind turbines on antipredator behavior in California ground squirrels (Spermophilus beecheyi). Biol Conserv 131: $410-420$

* Radford CA, Montgomery JC, Caiger P, Higgs DM (2012) Pressure and particle motion detection thresholds in fish: a re-examination of salient auditory cues in teleosts. J Exp Biol 215:3429-3435

Radford AN, Kerridge E, Simpson SD (2014) Acoustic communication in a noisy world: Can fish compete with anthropogenic noise? Behav Ecol 25:1022-1030

Ross D (1976) Mechanics of underwater noise. Pergamon Press, New York, NY

Ross D (2005) Ship sources of ambient noise. IEEE J Oceanic Eng 30:257-261

Sand O (1974) Recordings of saccular microphonic potentials in the perch. Comp Biochem Physiol A 47:387-390

Sand O, Enger PS, Karlsen HE, Knudsen F, Kvernstuen T (2000) Avoidance responses to infrasound in downstream migrating European silver eels, Anguilla anguilla. Environ Biol Fishes 57:327-336
Santulli A, Modica A, Messina C, Ceffa L and others (1999) Biochemical responses of European sea bass (Dicentrarchus labrax L.) to the stress induced by off shore experimental seismic prospecting. Mar Pollut Bull 38:1105-1114

* Sarà G, Dean JM, D'Amato D, Buscaino G and others (2007) Effect of boat noise on the behaviour of bluefin tuna Thunnus thynnus in the Mediterranean Sea. Mar Ecol Prog Ser 331:243-253

Scholik AR, Yan HY (2002) Effects of boat engine noise on the auditory sensitivity of the fathead minnow, Pimephales promelas. Environ Biol Fishes 63:203-209

Shafiei Sabet S, Neo YY, Slabbekoorn H (2015) The effect of temporal variation in sound exposure on swimming and foraging behaviour of captive zebrafish. Anim Behav 107:49-60

Shafiei Sabet S, Wesdorp K, Campbell J, Snelderwaard P, Slabbekoorn H (2016) Behavioural responses to sound exposure in captivity by two fish species with different hearing ability. Anim Behav 116:1-11

Sigray P, Andersson MH (2011) Particle motion measured at an operational wind turbine in relation to hearing sensitivity in fish. J Acoust Soc Am 130:200-207

* Simpson SD, Yan HY, Wittenrich ML, Meekan MG (2005) Response of embryonic coral reef fishes (Pomacentridae: Amphiprion spp.) to noise. Mar Ecol Prog Ser 287: 201-208

Simpson SD, Purser J, Radford AN (2015) Anthropogenic noise compromises antipredator behaviour in European eels. Glob Change Biol 21:586-593

* Smith ME, Kane AS, Popper AN (2004) Noise-induced stress response and hearing loss in goldfish (Carassius auratus). J Exp Biol 207:427-435

Spiga I, Fox J, Benson R (2012) Effects of short-and longterm exposure to boat noise on cortisol levels in juvenile fish. Adv Exp Med Biol 730:251-253

Vasconcelos RO, Amorim MCP, Ladich F (2007) Effects of ship noise on the detectability of communication signals in the Lusitanian toadfish. J Exp Biol 210:2104-2112

* Voellmy IK, Purser J, Flynn D, Kennedy P, Simpson SD, Radford AN (2014a) Acoustic noise reduces foraging success in two sympatric fish species via different mechanisms. Anim Behav 89:191-198

*Voellmy IK, Purser J, Simpson SD, Radford AN (2014b) Increased noise levels have different impacts on the antipredator behaviour of two sympatric fish species. PLOS ONE 9:e102946

Voellmy IK, Purser J, Simpson SD, Radford AN (2016) Effects of previous acoustic experience on behavioral responses to experimental sound stimuli and implications for research. Adv Exp Med Biol 875:1191-1196

Wale MA, Simpson SD, Radford AN (2013) Noise negatively affects foraging and antipredator behaviour in shore crabs. Anim Behav 86:111-118

Wilson M, Schack HB, Madsen PT, Surlykke A, Wahlberg M (2011) Directional escape behavior in allis shad (Alosa alosa) exposed to ultrasonic clicks mimicking an approaching toothed whale. J Exp Biol 214:22-29

Wolff DL (1967) Das Hörvermögen des Flussbarsches (Perca fluviatilis L.). Biol Zentbl 86:449-460

Wysocki LE, Ladich F (2005) Hearing in fishes under noise conditions. J Assoc Res Otolaryngol 6:28-36

*Wysocki LE, Dittami JP, Ladich F (2006) Ship noise and cortisol secretion in European freshwater fishes. Biol Conserv 128:501-508 